\title{
Feedforward Harmonic Mitigation Strategy for Single-Phase Voltage Source Converter
}

\author{
Qing Zhong (D), Junjie Feng, Gang Wang, and Haifeng Li 1 i \\ School of Electric Power, South China University of Technology, Guangzhou, China \\ Correspondence should be addressed to Qing Zhong; epqzhong@scut.edu.cn
}

Received 9 November 2017; Revised 20 December 2017; Accepted 21 December 2017; Published 28 January 2018

Academic Editor: Alessandro Lidozzi

Copyright (c) 2018 Qing Zhong et al. This is an open access article distributed under the Creative Commons Attribution License, which permits unrestricted use, distribution, and reproduction in any medium, provided the original work is properly cited.

\begin{abstract}
With the development of distributed generations (DGs), single-phase voltage source converter (SPVSC) has been widely used, but it brings about the problem of harmonic pollution to power grid. Hence, it is significant to explore the mechanism of harmonic injection from SPVSC and propose effective control strategies to mitigate the harmonic pollution. In this paper, a harmonic analysis model of SPVSC based on dynamic phasor (DP) has been established. With the model, the harmonics interaction between the ac side and the dc side can be analyzed with the consideration of the control strategies, which reveals the generation mechanism of the harmonics in SPVSC. Based on the mechanism, a feedforward harmonic mitigation strategy has been presented. The principle of the strategy is to add low-order harmonic signal to the PWM modulation signals to reduce the harmonic current on the ac side. The harmonic mitigation strategy not only has clear physical meaning and fast calculation, but also is robust for the uncertainty of parameters. Finally, the simulation and experiment results demonstrate the correctness of the model and the effectiveness of the harmonic mitigation strategy.
\end{abstract}

\section{Introduction}

Because of the capability of unity power factor and bidirectional energy flow, single-phase voltage source converters (SPVSC) have been widely applied in various industrial fields $[1,2]$, such as serving as the grid-connected interface of distributed generations (DGs) or microgrid with renewable energy systems [3,4]. However, due to the strong nonlinearity of power electronic devices, SPVSC also brings about the problem of harmonic pollution which has a negative impact on power grid [5-7]. Hence, it is necessary to analyze the mechanism of harmonic injection and propose effective suppression measurements, laying a solid foundation for the promotion of SPVSC.

Three-phase VSC generates high-order harmonics under normal situation, which can generally be filtered by low pass filter [8], while SPVSC generates not only high-order harmonics but also low-order harmonics [9] even in normal situation, which is hard to be eliminated. The harmonic current generated from SPVSC is eliminated mainly from two aspects $[10,11]$. One solution is to remove harmonic ripples in the voltage-loop and strengthen the antiharmonic disturbance capacity of current loop. Since harmonic ripples in the voltage-loop can be easily removed by employing low pass voltage filter [12] or notch filter [11], most studies focus on how to improve the performance of current-loop controller. Proportional Resonant (PR) controller [13, 14], which has the advantages of simplicity and zero steady-state error for tracking a sinusoidal signal, is widely used for selective harmonic elimination. However, it has high sensitivity to the frequency variations and may not be able to achieve a good effect, since a single PR controller only eliminates a single-order harmonic. Multiresonant controllers (MRCs) suppress harmonic distortions effectively by connecting PR controllers at harmonic frequency in parallel, but this causes heavy paralleling computation duty, particularly when highorder harmonics are required to be compensated. In the worst case, MRCs cause the system to be unstable [15]. In [16, 17], Repetitive Controller (RC) has been investigated which involved complicated analysis and designation. It is based on internal model principle and achieves zero steady-state error for tracking a sinusoidal signal. RC presented a much slower dynamic response than PR and MRCs. To achieve a minimum steady-state error while maintaining a fast-transient 
response, a hybrid controller by combining $\mathrm{PR}$ and $\mathrm{RC}$ has been proposed in $[12,18]$. However, the designation controller parameters were very complex to ensure the effectiveness of the control strategy and the stability of system.

The other solution is to add harmonic modulation signals to PWM modulated signals to offset harmonic currents on the ac side. Without additional controller, it can be implemented simply and has less computational burden. Moreover, the strategy not only can achieve a fast-dynamic response but also will not affect the stability of system no matter how many order harmonics need to be suppressed. Before the suppression strategy is put forward, it is important to establish an accurate harmonic analysis model which can reflect the harmonic generation mechanism. As an alternative to the traditional modeling approach [19, 20], dynamic phasor (DP) method is very useful for the harmonic analysis of SPVSC [21-23]. It was based on a linear time varying periodic (LTP) theory and considered the detailed switching dynamic of power electronic devices. DP was also very effective in revealing dynamical couplings between various quantities [24]; thus it was possible to analyze how harmonics transferred between ac and dc side of VSC.

To address the above issues, this paper develops a harmonic analysis model of SPVSC based on the dynamic phasor and the harmonic generation mechanism of SPVSC has been investigated comprehensively. According to such mechanism, a feedforward control strategy is put forward to mitigate the harmonics on grid side. The organization of this paper is as follows: in Section 2, the system configuration and time-domain model of SPVSC are shown and harmonic analysis model based on DP is investigated; in Section 3, the generation mechanism and transmission law of harmonic for SPVSC are analyzed; in Section 4, a feedforward harmonic mitigation strategy is proposed on the basis of the generation mechanism; in Sections 5 and 6, the simulation and experimental results are presented to verify the proposed model and harmonic mitigation strategy. Finally, the conclusion is drawn in Section 7.

\section{Harmonic Analyzing Model of SPVSC}

2.1. Time-Domain Model of SPVSC. The SPVSC topology studied in this paper is a single-phase $\mathrm{H}$ bridge voltage source converter as shown in Figure 1. $U_{s}$ is the ac source voltage. $R$ and $L$ are the equivalent resistance and impendence of the ac system. $I_{R}$ and $U_{R \text { ac }}$ are the ac side current and voltage of SPVSC, respectively. $U_{\mathrm{dc}}$ is the voltage on dc side. $C_{\mathrm{dc}}$ is the capacitor on the dc side. $R_{\mathrm{dc}}$ is the equivalent resistance of the dc loads. $I_{\mathrm{dc}}$ and $I_{l}$ are the output current and dc load current on the dc side. $V_{1}, V_{2}, V_{3}$, and $V_{4}$ are power electronic devices of converter.

The time-domain model of SPVSC can be described by

$$
\begin{aligned}
L \frac{d I_{R}}{d t} & =U_{s}-R I_{R}-U_{R \mathrm{ac}} \\
C_{\mathrm{dc}} \frac{d U_{\mathrm{dc}}}{d t} & =I_{\mathrm{dc}}-\frac{U_{\mathrm{dc}}}{R_{\mathrm{dc}}} .
\end{aligned}
$$

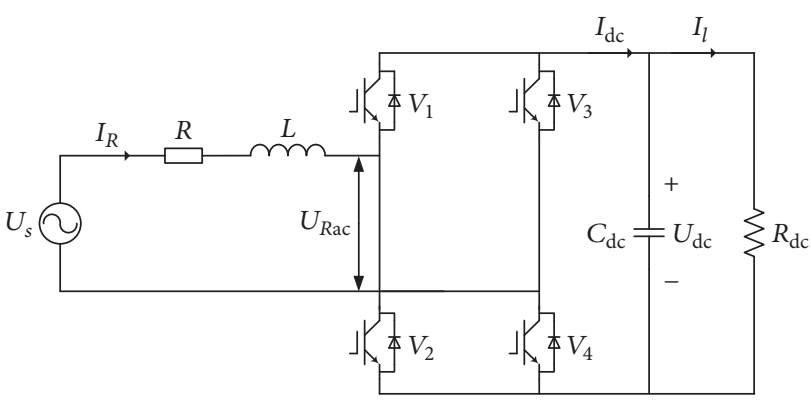

FIGURE 1: Topology of single-phase VSC.

The switching function is used to describe the interaction between the ac and dc side of SPVSC, so $U_{R \mathrm{ac}}$ and $I_{\mathrm{dc}}$ in (1) can be given as

$$
\begin{gathered}
U_{R \mathrm{ac}}=S_{R} U_{\mathrm{dc}} \\
I_{\mathrm{dc}}=S_{R} I_{R},
\end{gathered}
$$

where $S_{R}$ is the switching function of SPVSC. When $V_{1}$ and $V_{4}$ are switched on, it is 1 , and when $V_{2}$ and $V_{3}$ are on, it is -1 . $S_{R}$ is related to the control strategy and determined by the PWM signal.

As shown in Figure 2, double closed-loop control strategy is occasionally employed in the control of converter. The dclink voltage out-loop is controlled by a proportional integral (PI) controller and the peak value of reference current $I_{m \text { _ref }}$ is obtained. $I_{m_{-} \text {ref }}$ is multiplied by $\cos \theta$, which is the ac system voltage phase cosine captured by phase locked loop (PLL), so as to operate at unity power factor. The current inner loop is controlled by proportional $(P)$ controller to track the ac side current reference value $I_{t \_r e f}$.

What needs to be specially mentioned is that, considering the phase delay in the sampling, grid voltage feedforward sampling value $U_{\text {st }}$ is obtained by multiplying the fundamental RMS of $U_{s}$ with $\cos \theta$. After subtracting $U_{\text {st }}$ from the output value of current controller and being divided by $U_{\mathrm{dc} \_ \text {ref }}$, the modulation signal of SPVSC is obtained

$$
U_{m}=\frac{1}{U_{\text {dc_ref }}}\left[U_{\text {st }}-K_{\text {ip }}\left(I_{t_{-} \text {ref }}-I_{R}\right)\right],
$$

where $K_{\text {ip }}$ is the proportional regulation gain of current inner loop, $U_{\text {st }}$ is the sampling value of grid voltage, $U_{\mathrm{dc} \text { ref }}$ is the reference of dc voltage, and $I_{R}$ and $I_{t \_ \text {ref }}$ are the actual value and reference value of ac side current, respectively. $I_{m \_ \text {ref }}$ is the peak value of reference current which can be obtained by $I_{m \_ \text {ref }}=\sqrt{2} u_{\mathrm{dc}} I_{\mathrm{dc}} / U_{\mathrm{rms}}$.

2.2. Dynamic Phasor Harmonic Analysis Model of SPVSC. The SPVSC time-domain model described by (1) and (2) can be transformed into dynamic phasor model, and the $k$-order 


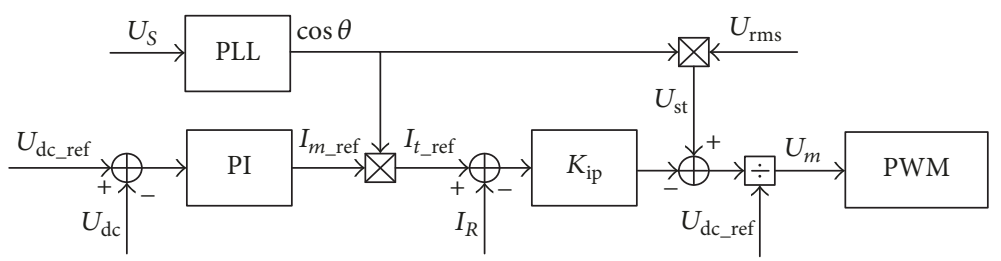

FIGURE 2: Double closed-loop control structure of voltage and current.

dynamic phase equation of the ac side current and the dc side voltage is expressed as

$$
\begin{aligned}
\frac{d\left\langle I_{R}\right\rangle_{k}}{d t}= & -\left(\frac{R}{L}+j k \omega_{s}\right)\left\langle I_{R}\right\rangle_{k}-\frac{\left\langle U_{\mathrm{dc}} S_{R}\right\rangle_{k}}{L} \\
& +\frac{\left\langle U_{s}\right\rangle_{k}}{L} \\
\frac{d\left\langle U_{\mathrm{dc}}\right\rangle_{k}}{d t}= & -\left(\frac{1}{R_{\mathrm{dc}} C_{\mathrm{dc}}}+j k \Theta_{s}\right)\left\langle U_{\mathrm{dc}}\right\rangle_{k}+\frac{\left\langle I_{R} S_{R}\right\rangle_{k}}{C_{\mathrm{dc}}},
\end{aligned}
$$

where $\Phi_{s}=2 \pi / T$ is the angular frequency and $\langle\cdot\rangle_{k}$ denotes the $k$ th dynamic phasor.

$\left\langle U_{\mathrm{dc}} S_{R}\right\rangle_{k}$ and $\left\langle I_{R} S_{R}\right\rangle_{k}$ are the convolution of switching function and dc side voltage or ac side current, respectively, which represents the interaction of harmonics between the ac and dc sides of SPVSC. It can be described by

$$
\begin{aligned}
\left\langle U_{\mathrm{dc}} S_{R}\right\rangle_{k} & =\sum_{i}\left\langle S_{R}\right\rangle_{k-i}\left\langle u_{\mathrm{dc}}\right\rangle_{i} \\
\left\langle I_{R} S_{R}\right\rangle_{k} & =\sum_{i}\left\langle S_{R}\right\rangle_{k-i}\left\langle I_{R}\right\rangle_{i} .
\end{aligned}
$$

In this paper, SPWM modulation with fixed switching frequency is adopted, so the dynamic phasor of switching function is determined by $U_{m}$ and can be given as

$$
\begin{aligned}
\left\langle S_{R}\right\rangle_{k} & =\left\langle U_{m}\right\rangle_{k} \\
& =\frac{1}{U_{\text {dc_ref }}}\left[\left\langle U_{\text {st }}\right\rangle_{k}-K_{\mathrm{iP}}\left(\left\langle I_{t_{-} \text {ref }}\right\rangle_{k}-\left\langle I_{R}\right\rangle_{k}\right)\right] .
\end{aligned}
$$

Since $U_{\text {st }}$ and $I_{t \_ \text {ref }}$ have only the fundamental component, the $k$ th dynamic phasor is equivalent to 0 , except $\left\langle U_{\text {st }}\right\rangle_{1} \neq 0$ and $\left\langle I_{t \text { ref }}\right\rangle_{1} \neq 0$. This paper is mainly aimed at the lowerorder harmonic component within 13 orders, so the highorder component of the dynamic phasor of the switching function can be neglected. Equation (6) can be simplified as

$$
\begin{aligned}
& \left\langle S_{R}\right\rangle_{k} \\
& = \begin{cases}\frac{\left\langle U_{\mathrm{st}}\right\rangle_{1}-K_{\mathrm{iP}}\left\langle I_{t \text { ref }}\right\rangle_{1}}{U_{\mathrm{dc} \_ \text {ref }}}+\frac{K_{\mathrm{iP}}\left\langle I_{R}\right\rangle_{1}}{U_{\mathrm{dc} \_ \text {ref }}}, & k=1 \\
\frac{K_{\mathrm{iP}}\left\langle I_{R}\right\rangle_{k}}{U_{\mathrm{dc} \_ \text {ref }}}, & k=2, \ldots, 13 .\end{cases}
\end{aligned}
$$

By substituting (7) into (4), the $k$ th dynamic phasor equation of the ac side current and the dc side voltage is obtained as follows:

$$
\begin{aligned}
\frac{d\left\langle I_{R}\right\rangle_{k}}{d t}= & -\left(\frac{R}{L}+j k \omega_{s}\right)\left\langle I_{R}\right\rangle_{k}+\frac{\left\langle U_{s}\right\rangle_{k}}{L} \\
& -\frac{K_{\mathrm{iP}}}{U_{\mathrm{dc} \_ \text {ref }} L} \sum_{i}\left\langle I_{R}\right\rangle_{k-i}\left\langle u_{\mathrm{dc}}\right\rangle_{i} \\
& -\frac{\left\langle U_{\mathrm{st}}\right\rangle_{1}-K_{\mathrm{iP}}\left\langle I_{t \_ \text {ref }}\right\rangle_{1}}{U_{\mathrm{dc} \_ \text {ref }} L}\left\langle u_{\mathrm{dc}}\right\rangle_{k-1} \\
& -\frac{\left\langle U_{\mathrm{st}}\right\rangle_{-1}-K_{\mathrm{iP}}\left\langle I_{t \_ \text {ref }}\right\rangle_{-1}}{U_{\mathrm{dc} \_ \text {ref }} L}\left\langle u_{\mathrm{dc}}\right\rangle_{k+1}, \\
\frac{d\left\langle u_{\mathrm{dc}}\right\rangle_{k}}{d t}= & -\left(\frac{1}{R_{\mathrm{dc} C} C}+j k \omega_{s}\right)\left\langle u_{\mathrm{dc}}\right\rangle_{k} \\
& +\frac{\left\langle U_{\mathrm{st}}\right\rangle_{1}-K_{\mathrm{iP}}\left\langle I_{t \_ \text {ref }}\right\rangle_{1}}{U_{\mathrm{dc} \_ \text {ref }} C}\left\langle I_{R}\right\rangle_{k-1} \\
& +\frac{\left\langle U_{\mathrm{st}}\right\rangle_{-1}-K_{\mathrm{iP}}\left\langle I_{t \_ \text {ref }}\right\rangle_{-1}}{U_{\mathrm{dc} \_ \text {ref }} C}\left\langle I_{R}\right\rangle_{k+1} \\
& +\frac{K_{\mathrm{iP}}}{U_{\mathrm{dc} \_ \text {ref }} C} \sum_{i}\left\langle I_{R}\right\rangle_{k-i}\left\langle I_{R}\right\rangle_{i},
\end{aligned}
$$

where $\left\langle I_{t_{-} \text {ref }}\right\rangle_{-1}=\left\langle I_{t_{-} \text {ref }}\right\rangle_{1}^{*}$ and $\left\langle U_{\text {st }}\right\rangle_{-1}=\left\langle U_{\text {st }}\right\rangle_{1}^{*}$, according to the conjugate property of dynamic phasor. In the convolution $\sum\left\langle I_{R}\right\rangle_{k-i}\left\langle u_{\mathrm{dc}}\right\rangle_{i}$ and $\sum\left\langle I_{R}\right\rangle_{k-i}\left\langle I_{R}\right\rangle_{i}$, the product of two small quantities can be neglected. It means that only the items including dc component of voltage on dc side or fundamental current on ac side should be considered. Therefore, the accumulation of items in (8) and (9) can be simplified as

$$
\begin{aligned}
\sum_{i}\left\langle I_{R}\right\rangle_{k-i}\left\langle u_{\mathrm{dc}}\right\rangle_{i}= & \left\langle I_{R}\right\rangle_{k}\left\langle u_{\mathrm{dc}}\right\rangle_{0}+\left\langle I_{R}\right\rangle_{1}\left\langle u_{\mathrm{dc}}\right\rangle_{k-1} \\
& +\left\langle I_{R}\right\rangle_{1}^{*}\left\langle u_{\mathrm{dc}}\right\rangle_{k+1} \\
\sum_{i}\left\langle I_{R}\right\rangle_{k-i}\left\langle I_{R}\right\rangle_{i}= & 2\left\langle I_{R}\right\rangle_{k-1}\left\langle I_{R}\right\rangle_{1} \\
& +2\left\langle I_{R}\right\rangle_{k+1}\left\langle I_{R}\right\rangle_{1}^{*}
\end{aligned}
$$

The $k$ th dynamic phasor of current on ac side and voltage on dc side can be obtained by solving (8) and (9). The calculation results are the different order harmonics of current on ac side and voltage on dc side. Therefore, the 


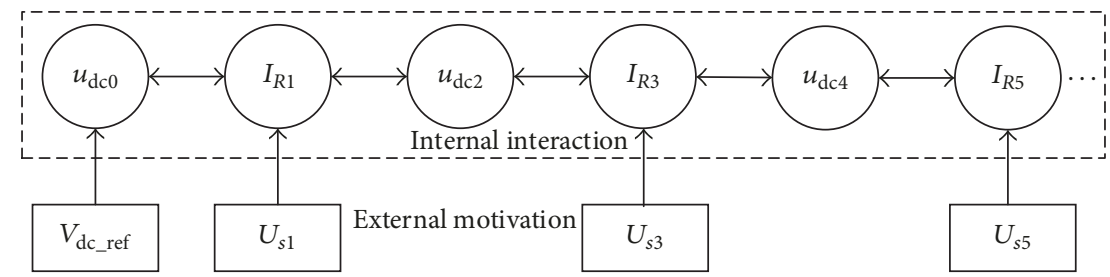

FIgURE 3: Harmonic interaction law of single-phase VSC.

dynamic phasor model of SPVSC can be used to analyze the generation mechanism of harmonic.

\section{Mechanism of SPVSC Harmonic Generations}

In the steady state, the dc component of dc side voltage is equivalent to its reference; that is, $\left\langle u_{\mathrm{dc}}\right\rangle_{0}=V_{\mathrm{dc} \_ \text {ref }}$. The differential of the dynamic phasor of ac side current and the dc side voltage can be neglected, so $d\left\langle I_{R}\right\rangle_{k} / d t=0$ and $d\left\langle u_{\mathrm{dc}}\right\rangle_{k} / d t=0$. The harmonic generation mechanism of SPVSC under steady-state conditions is analyzed below. in

The dc voltage on dc side can be obtained by (8), as shown

$$
\begin{aligned}
\frac{1}{R_{\mathrm{dc}}}\left\langle u_{\mathrm{dc}}\right\rangle_{0} & \\
= & \frac{\left\langle U_{\mathrm{st}}\right\rangle_{1}-K_{\mathrm{iP}}\left(\left\langle I_{t_{\_} \text {ref }}\right\rangle_{1}-\left\langle I_{R}\right\rangle_{1}\right)}{U_{\mathrm{dc} \_ \text {ref }}}\left\langle I_{R}\right\rangle_{1}^{*} \\
& +\frac{\left\langle U_{\mathrm{st}}\right\rangle_{1}^{*}-K_{\mathrm{iP}}\left(\left\langle I_{t \_ \text {ref }}\right\rangle_{1}^{*}-\left\langle I_{R}\right\rangle_{1}^{*}\right)}{U_{\mathrm{dc} \_ \text {ref }}}\left\langle I_{R}\right\rangle_{1} .
\end{aligned}
$$

Equation (11) can describe the interaction between the dc voltage on dc side and the fundamental current on ac side.

Similarly, the fundamental current on ac side can be further written as

$$
\begin{aligned}
\left(R+j \omega_{s} L\right)\left\langle I_{R}\right\rangle_{1} \\
=-\frac{\left\langle U_{\text {st }}\right\rangle_{1}-K_{\mathrm{iP}}\left(\left\langle I_{t_{\_} \text {ref }}\right\rangle_{1}-\left\langle I_{R}\right\rangle_{1}\right)}{U_{\mathrm{dc \_ ref}}}\left\langle u_{\mathrm{dc}}\right\rangle_{0} \\
\\
\quad-\frac{\left\langle U_{\mathrm{st}}\right\rangle_{1}^{*}-K_{\mathrm{iP}}\left(\left\langle I_{t \_ \text {ref }}\right\rangle_{1}^{*}-\left\langle I_{R}\right\rangle_{1}^{*}\right)}{U_{\mathrm{dc} \_ \text {ref }}}\left\langle u_{\mathrm{dc}}\right\rangle_{2} \\
+\left\langle U_{s}\right\rangle_{1} .
\end{aligned}
$$

Therefore, the fundamental current on ac side not only interacts with the dc voltage on dc side, but also interacts with the 2 nd harmonic voltage on dc side.
The 2nd harmonic voltage on $\mathrm{dc}$ side and the 3rd harmonic current on ac side can be expressed as follows:

$$
\begin{aligned}
& \left(\frac{1}{R_{\mathrm{dc}}}+j 2 C \omega_{s}\right)\left\langle u_{\mathrm{dc}}\right\rangle_{2} \\
& =-\frac{\left\langle U_{\text {st }}\right\rangle_{1}-K_{\mathrm{iP}}\left(\left\langle I_{t_{\text {_ref }}}\right\rangle_{1}-\left\langle I_{R}\right\rangle_{1}\right)}{V_{\text {dc_ref }}}\left\langle I_{R}\right\rangle_{1} \\
& -\frac{\left\langle U_{\text {st }}\right\rangle_{1}^{*}-K_{\mathrm{iP}}\left(\left\langle I_{t \_ \text {ref }}\right\rangle_{1}^{*}-\left\langle I_{R}\right\rangle_{1}^{*}\right)}{V_{\text {dc_ref }}}\left\langle I_{R}\right\rangle_{3} \\
& +\frac{K_{\mathrm{iP}}\left\langle I_{R}\right\rangle_{3}\left\langle I_{R}\right\rangle_{1}^{*}}{V_{\mathrm{dc \_ ref}}}, \\
& \left(R+j 3 \omega_{s} L+K_{\mathrm{iP}}\right)\left\langle I_{R}\right\rangle_{3} \\
& =-\frac{\left\langle U_{\mathrm{st}}\right\rangle_{1}-K_{\mathrm{iP}}\left(\left\langle I_{t_{\_} \text {ref }}\right\rangle_{1}-\left\langle I_{R}\right\rangle_{1}\right)}{V_{\mathrm{dc} \_ \text {ref }}}\left\langle u_{\mathrm{dc}}\right\rangle_{2} \\
& -\frac{\left\langle U_{\text {st }}\right\rangle_{1}^{*}-K_{\mathrm{iP}}\left(\left\langle I_{t \_ \text {ref }}\right\rangle_{1}^{*}-\left\langle I_{R}\right\rangle_{1}^{*}\right)}{V_{\mathrm{dc \_ ref}}}\left\langle u_{\mathrm{dc}}\right\rangle_{4} \\
& +\left\langle U_{s}\right\rangle_{3} .
\end{aligned}
$$

In (13), the state variables on the right are $\left\langle I_{R}\right\rangle_{1}$ and $\left\langle I_{R}\right\rangle_{3}$, which indicates that the 2 nd harmonic voltage on dc side not only interacts with the fundamental current on ac side, but also interacts with the 3rd harmonic current on ac side. Similarly, it can be obtained from (14) that the 3rd harmonic current on ac side not only interacts with the 2nd harmonic voltage on dc side, but also interacts with the 4 th harmonic voltage on dc side. Meanwhile, the 3rd voltage background harmonic of power grid will also induce the 3rd harmonic current on ac side. Therefore, the generation mechanism and interaction law of harmonic current on ac side and harmonic voltage on dc side can be summarized as in Figure 3.

In Figure 3, $u_{\mathrm{dci}}$ and $I_{R i}$ are $i$ th harmonic voltage on dc side and $i$ th harmonic current on ac side, respectively. $V_{\mathrm{dc} \text { ref }}$ is the dc voltage reference in controller. $U_{s i}$ is $i$ th harmonic voltage of ac side source. The single arrow represents the effect of external excitation on harmonics, and the double arrow represents the interaction between two variables.

There are two reasons for the lower-order harmonic generation of SPVSC, that is, external excitation and internal interaction. From the internal interaction, SPVSC will generate a series of odd harmonic currents on ac side and a series of even harmonic voltages on dc side. From the 
external excitation relationship, it can be concluded that when the voltage of power grid is distorted, it will aggravate the harmonic generation from SPVSC and lead to more serious harmonic pollution to the power grid.

\section{Harmonic Current Mitigation Strategy}

In order to reduce the harmonic currents injecting to the power grid, a feedforward harmonic mitigation strategy is investigated based on the results in Section 3. Its principle is to superimpose low-order harmonic signal into the PWM modulation wave, which can cut off the external incentive and internal transfer path of harmonic propagation, thus eliminating the lower-order harmonic current on ac side.

Aiming at $N$ th $(N=3,5, \ldots, 13)$ harmonic currents on ac side, (4) can be simplified as

$$
\left(R+j k \omega_{s} L\right)\left\langle I_{R}\right\rangle_{N}=-\sum_{i}\left\langle S_{R}\right\rangle_{N-i}\left\langle U_{\mathrm{dc}}\right\rangle_{i}+\left\langle U_{s}\right\rangle_{N} .
$$

The harmonic currents on ac side are mainly induced by the grid voltage distortions and the internal interaction between the harmonic voltages on dc side just shown in Figure 3. The grid voltage distortions $\left\langle U_{s}\right\rangle_{N}$ are normally uncontrolled, mainly induced by other nonlinear loads. However, the ac voltage of SPVSC $\sum_{i}\left\langle S_{R}\right\rangle_{N-i}\left\langle U_{\mathrm{dc}}\right\rangle_{i}$ can be easily controlled by adjusting controller. It can be implied from (15) that $\left\langle S_{R}\right\rangle_{N}\left\langle U_{\mathrm{dc}}\right\rangle_{0}$ can be utilized to offset the harmonic currents generated by $\left\langle U_{s}\right\rangle_{N}$ and $\sum_{i \neq 0}\left\langle S_{R}\right\rangle_{N-i}\left\langle U_{\mathrm{dc}}\right\rangle_{i}$. If the right side of (15) is equal to 0 , the internal interaction between the ac and dc side harmonics and external excitation from grid voltage distortions can be offset; thus the $N$ th harmonic current on ac side can be eliminated effectively.

From (6) and (8), the lower-order harmonic components $\langle\Delta S\rangle_{N}$ which should be superimposed on the PWM signal can be derived as follows:

$\langle\Delta S\rangle_{N}$

$$
=\frac{\left(\left(\left(\left\langle U_{\mathrm{st}}\right\rangle_{1}-K_{\mathrm{iP}}\left(\left\langle I_{t_{-} \text {ref }}\right\rangle_{1}-\left\langle I_{R}\right\rangle_{1}\right)\right) / U_{\mathrm{dc} \_ \text {ref }}\right)\left\langle u_{\mathrm{dc}}\right\rangle_{N-1}+\left(\left(\left\langle U_{\mathrm{st}}\right\rangle_{1}^{*}-K_{\mathrm{iP}}\left(\left\langle I_{t_{-} \text {ref }}\right\rangle_{1}^{*}-\left\langle I_{R}\right\rangle_{1}^{*}\right)\right) / U_{\mathrm{dc} \_ \text {ref }}\right)\left\langle u_{\mathrm{dc}}\right\rangle_{N+1}-\left\langle U_{s}\right\rangle_{N}\right)}{\left\langle u_{\mathrm{dc}}\right\rangle_{0}} .
$$

Above all, the feedforward compensation control strategy is implemented by superimposing lower-order harmonic components in the PWM signal to suppress the low-order harmonic currents on ac side. The control block diagram is shown in Figure 4. The harmonic voltage component on $\mathrm{dc}$ side and the background harmonic voltage on ac side are detected in real time. According to (16), the amplitude and phase angle of the Nth harmonic components needed to be superposed in the PWM signals are obtained, so as to suppress the harmonic current on ac side dynamically.

The harmonic mitigation strategy not only has clear physical meaning and fast calculation speed, but also will not be affected by the uncertainty of circuit parameters which can be seen from (16). Moreover, without additional controller, it avoids the complex parameter design and will not affect the stability of the system.

\section{Simulation Results}

In order to verify the correctness of the harmonic analysis model, a SPVSC model is set up in MATLAB/Simulink. The key parameters for the simulation model are listed in Table 1.

The control strategy is shown in Figure 2, which is voltage and circuit double closed-loop control. The simulation results and the theoretical results of the harmonic currents on ac side and the harmonic voltages on dc side are shown in Tables 2 and 3, respectively. The simulation results of the amplitude and angle of the harmonic currents on ac side and the harmonic voltages on $\mathrm{dc}$ side are well-matched with those obtained by the harmonic analysis model. There are a series of low-order odd harmonic currents on the ac side, in which the 3rd harmonic current is dominant. The amplitude decreases with the harmonic order increasing. There are series of low-order even harmonic voltages on $\mathrm{dc}$ side. The 2 nd harmonic voltage is the most obvious. The harmonic content is obviously reduced with the increase of the harmonic order. Therefore, the correctness of the loworder harmonic analysis model of SPVSC with closed-loop control strategy is verified.

In order to verify the harmonic transmission law of SPVSC, injecting 3rd and 5th voltage background harmonics to power grid, respectively, the harmonic spectra of the ac side current and the dc side voltage are obtained, which is shown in Figure 5. The black bar represents the situation without background harmonic voltage. The red bar represents the situation with 3rd background harmonic voltage, and the blue bar represents the situation with 5th background harmonic voltage.

It can be seen that when the power grid contains 3rd background harmonic voltage, the third harmonic current on ac side increased significantly, and the 4th harmonic voltage on dc side also increased because of the interaction between the ac side and dc side. Simultaneously, it passes back to ac side and generates 5th harmonic current. But after the second transmission, the impact on 5th harmonic current is weak. Similarly, when the grid contains 5th background harmonics voltage, the 6th harmonic voltage on dc side increased because of the impact of 5th harmonic current on ac side. But when it is passed back to the 7th harmonic current 


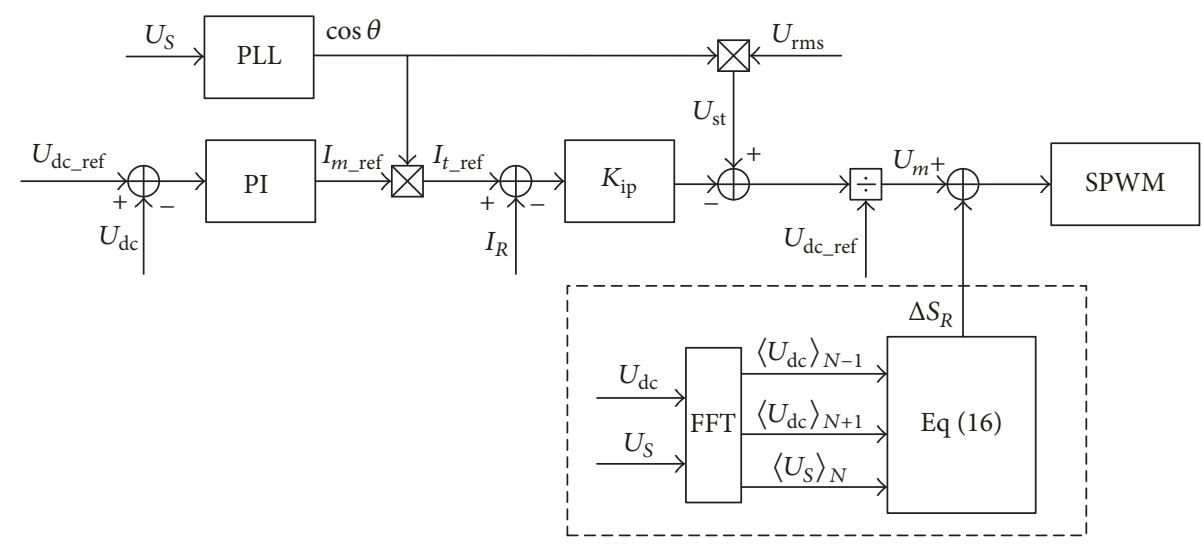

FIGURE 4: Control block diagram of injected $N$-order modulation wave.

TABLE 1: Simulation parameters.

\begin{tabular}{lcc}
\hline Parameter & Meaning & Value \\
\hline$U_{s}$ & RMS of ac source voltage & $220 \mathrm{~V}$ \\
$R, L$ & Impedance of the ac system & $0.02 \Omega / 3 \mathrm{mH}$ \\
$C_{\mathrm{dc}}$ & Capacitor on dc side & $3400 \mu \mathrm{F}$ \\
$R_{\mathrm{dc}}$ & Load resistance & $10 \Omega$ \\
$V_{\mathrm{dc} \_ \text {ref }}$ & Reference of dc voltage & $428 \mathrm{~V}$ \\
\hline
\end{tabular}

TABLE 2: Comparison of theoretical results and simulation results of harmonic currents on ac side.

\begin{tabular}{lcccc}
\hline \multirow{2}{*}{ Frequency } & \multicolumn{2}{c}{ Simulation result } & \multicolumn{2}{c}{ Calculation result } \\
& Magnitude (A) & Angle $\left(^{\circ}\right)$ & Magnitude (A) & Angle $\left(^{\circ}\right)$ \\
\hline $50 \mathrm{~Hz}$ & 124.43 & 2.7 & 124.61 & 2.5 \\
$150 \mathrm{~Hz}$ & 1.65 & 221.4 & 1.69 & 230.2 \\
$250 \mathrm{~Hz}$ & 0.11 & 118.8 & 0.08 & 116.6 \\
\hline
\end{tabular}

TABLE 3: Comparison of theoretical results and simulation results of harmonic voltages on dc side.

\begin{tabular}{lcccc}
\hline \multirow{2}{*}{ Frequency } & \multicolumn{2}{c}{ Simulation result } & \multicolumn{2}{c}{ Calculation result } \\
& Magnitude $(\mathrm{V})$ & Angle $\left({ }^{\circ}\right)$ & Magnitude $(\mathrm{V})$ & Angle $\left(^{\circ}\right)$ \\
\hline $0 \mathrm{~Hz}$ & 428.10 & 90.0 & 430.16 & 90.0 \\
$100 \mathrm{~Hz}$ & 20.57 & 183.7 & 20.60 & 183.8 \\
$200 \mathrm{~Hz}$ & 0.33 & 49.7 & 0.33 & 52.65 \\
\hline
\end{tabular}

on ac side, the impact is weak. The harmonic transfer law shown in Figure 3 can be validated.

In order to verify the effectiveness of the feedforward harmonic mitigation strategy, the simulation is carried out and the dynamic compensation effect can be observed by changing the system conditions. Initially, the grid voltage has $0.1 \mathrm{pu} 3 \mathrm{rd}$ and $0.05 \mathrm{pu} 5$ th harmonic distortions. At $0.4 \mathrm{~s}$, the feedforward harmonic mitigation strategy is employed and the low-order harmonic signals are superimposed to PWM modulated waves. At $0.5 \mathrm{~s}$, the grid voltage changes suddenly, only containing $0.01 \mathrm{pu} 5$ th background harmonic voltage. At $0.7 \mathrm{~s}$, the grid voltage becomes undistorted, and the load resistance on dc side changes from $10 \Omega$ to $6.67 \Omega$. At $0.9 \mathrm{~s}$, the harmonic mitigation link is turned off. Figure 6 presents the harmonic injection component of PWM signals. Table 4 presents the harmonic currents on ac side before and after the harmonic mitigation strategy being employed.

Before the feedforward harmonic mitigation strategy is employed, there are a large number of 3rd and 5th harmonic currents on ac side, which amplitudes are $6.48 \mathrm{~A}$ and $2.85 \mathrm{~A}$, respectively. When the harmonic mitigation strategy is employed, the harmonic is effectively suppressed and the amplitude decreased to $0.37 \mathrm{~A}$ and $0.09 \mathrm{~A}$, respectively. At $0.5 \mathrm{~s}$ and $0.7 \mathrm{~s}$, the background harmonic voltages in grid and load are changed abruptly, but the harmonic suppression is still effective. Moreover, low-order harmonic signal superimposing to PWM can quickly track the changes of system conditions, to suppress the harmonics current on ac side dynamically. Above all, the effectiveness of the harmonic mitigation strategy is verified.

\section{Experimental Results}

The experimental setup of single-phase voltage source converter is shown in Figure 7. The inductance on the ac side is $6 \mathrm{mH}$. The capacitance and resistance on dc side are $3400 \mu \mathrm{F}$ and $100 \Omega$. The carrier wave frequency is $7500 \mathrm{~Hz}$. The converter uses the intelligent power module (IPM) and the controller uses DSP TMS320F28335. The control strategy is the same as simulation.

The grid voltage is used as the system voltage on ac side, in which RMS is $220 \mathrm{~V}$. The measurement results show that the most obvious background harmonic voltage is $3 \mathrm{rd}$, 5th, and 7 th harmonic voltage, so the experiment mainly aims at 3rd, 5th, and 7th harmonic current to verify the effectiveness of the proposed suppression strategy. By inducing the harmonic component feedforward of the ac side voltage and the dc side voltage, the amplitude and phase angle of harmonic signal which needs to be superimposed in PWM modulation wave can be obtained by controller and applied to the converter. The Fluke 435 is used to measure the voltage and current wave on the ac side of SPVSC and analyze the spectrum characteristics of ac current. In this section, a comparison between multiresonant control strategy $[14,15]$ and the proposed 
TABLE 4: The harmonic current on ac side before and after $N$-order modulated wave injection (A).

\begin{tabular}{lccccc}
\hline $\begin{array}{l}\text { Harmonic } \\
\text { order }\end{array}$ & $\begin{array}{c}0 \sim 0.4 \mathrm{~s} \\
\text { without }\end{array}$ & $\begin{array}{c}0.4 \sim 0.5 \mathrm{~s} \\
\text { with }\end{array}$ & $\begin{array}{c}0.5 \sim 0.7 \mathrm{~s} \\
\text { with }\end{array}$ & $\begin{array}{c}0.7 \sim 0.9 \mathrm{~s} \\
\text { with }\end{array}$ & $\begin{array}{c}0.9 \sim 1.1 \mathrm{~s} \\
\text { without }\end{array}$ \\
\hline Fund & 123.80 & 123.82 & 124.48 & 184.49 & 184.36 \\
3rd & 6.48 & 0.37 & 0.23 & 0.45 & 2.51 \\
5th & 2.85 & 0.09 & 0.07 & 0.11 & 0.23 \\
\hline
\end{tabular}

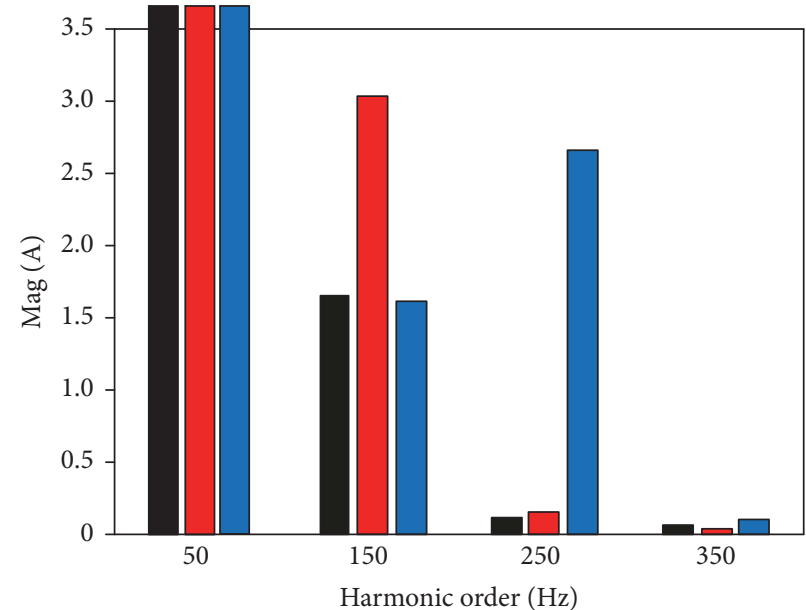

None

Third

Fifth

(a) Spectrum of current on ac side

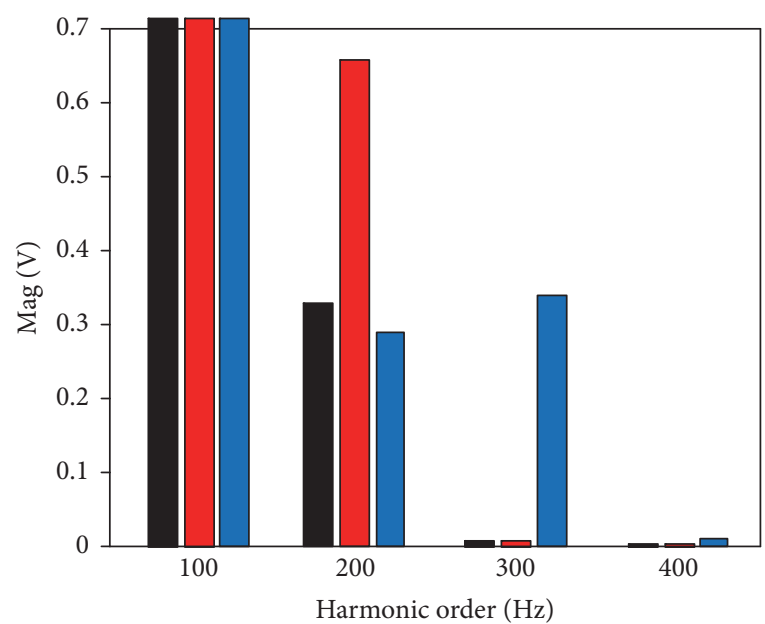

None

Third

Fifth

(b) Spectrum of voltages on dc side

FIGURE 5: The grid voltage contains third and fifth harmonic.

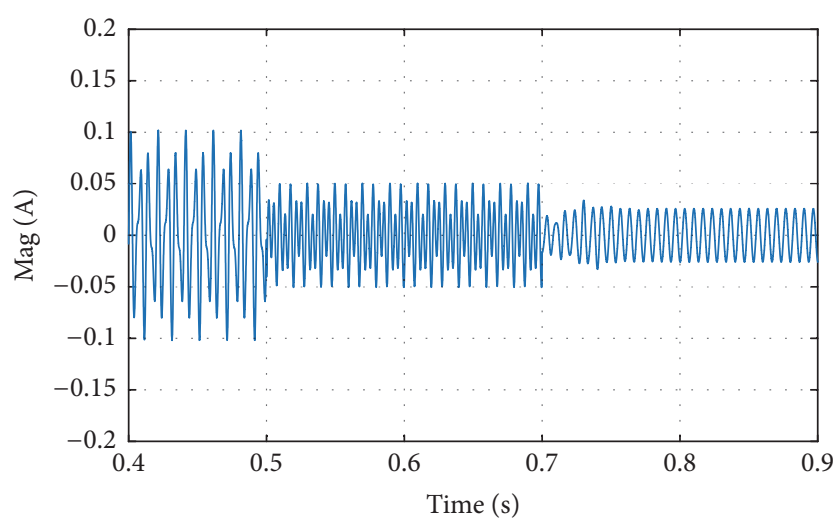

Figure 6: Harmonic injection component of PWM modulated wave.

feedforward harmonic mitigation strategy is carried out. The waveforms and harmonics tables of current on ac side without harmonic mitigation strategy, with multiresonant control strategy and with the proposed strategy, are shown in Figures 8,9 , and 10 , respectively.

From the experimental results, it can be found that after the multiresonant control strategy is employed, the total harmonic distortion of current (THDI) decreases from $4.7 \%$ to $3.5 \%$, and the harmonic content of $3 \mathrm{rd}, 5$ th, and 7 th

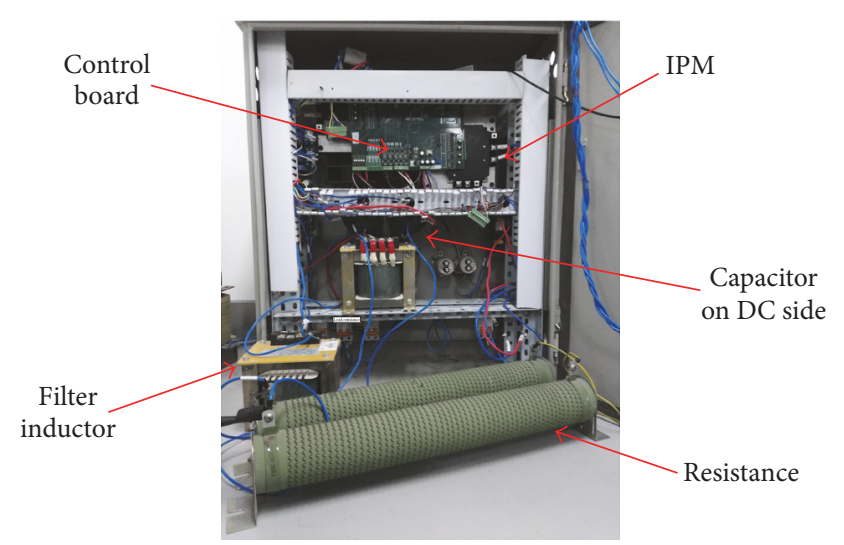

FIGURE 7: Experimental setup of single-phase voltage source converter.

current decreases from $3.3 \%$ to $1.5 \%, 2.2 \%$ to $2.1 \%$, and $1.5 \%$ to $0.9 \%$, respectively. However, after the feedforward harmonic mitigation strategy is employed, THDI decreases from $4.7 \%$ to $2.5 \%$, and the harmonic content of $3 \mathrm{rd}$, 5 th, and 7 th harmonic current decreases to $0.8 \%, 1.6 \%$, and $1.1 \%$, respectively. It is clearly shown that the proposed strategy has better performance than multiresonant control strategy, which has verified the effectiveness of the proposed harmonic 


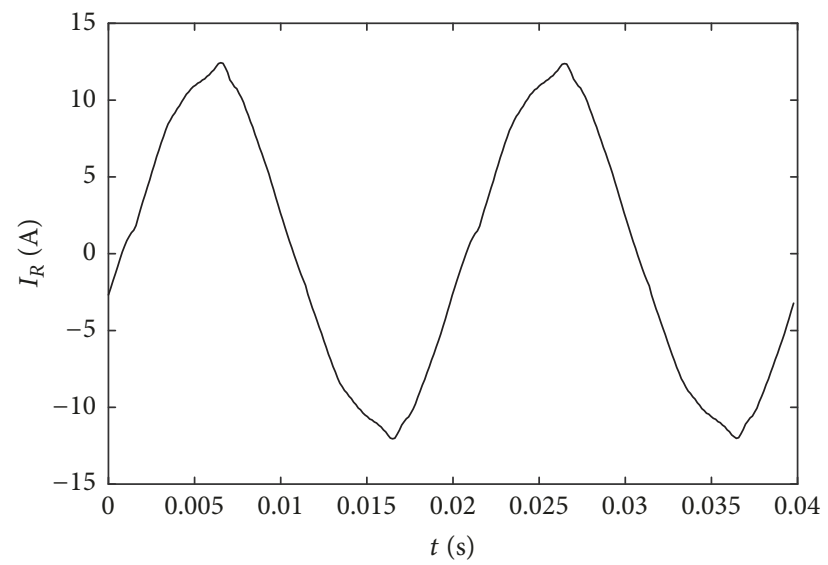

(a) Waveform

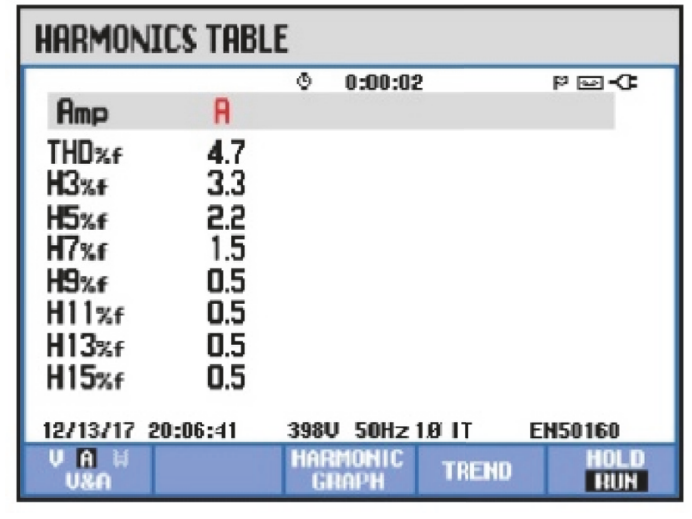

(b) Harmonics table

FIGURE 8: Waveform and harmonics table of current on ac side without harmonic mitigation strategy.

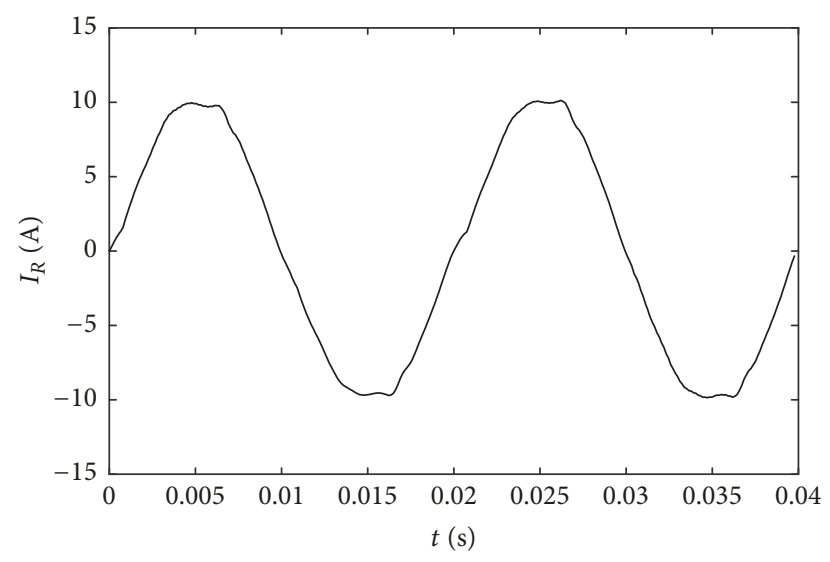

(a) Waveform

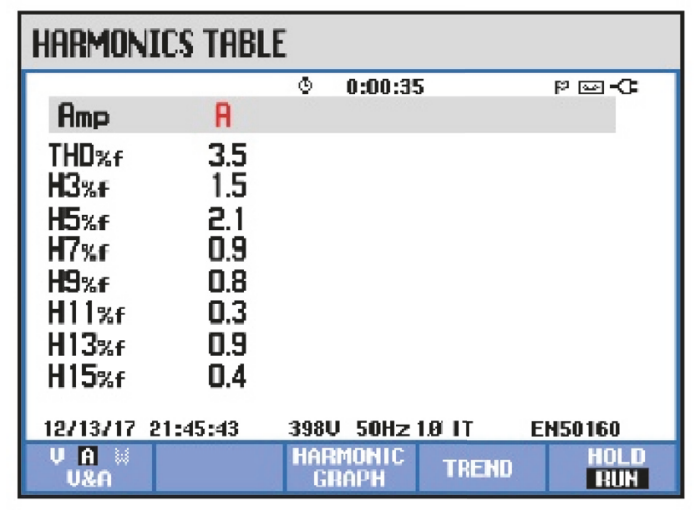

(b) Harmonics table

FIGURE 9: Waveform and harmonics table of current on ac side with multiresonant control strategy.

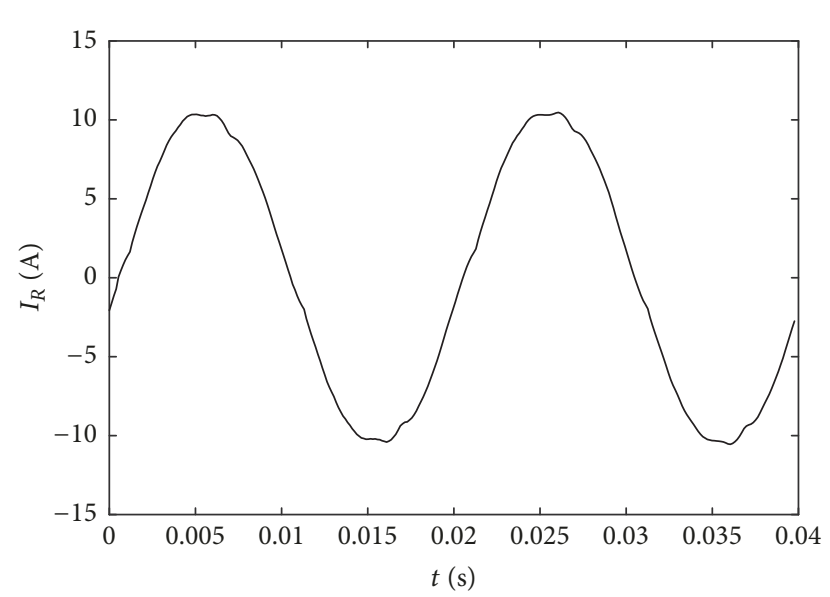

(a) Waveform

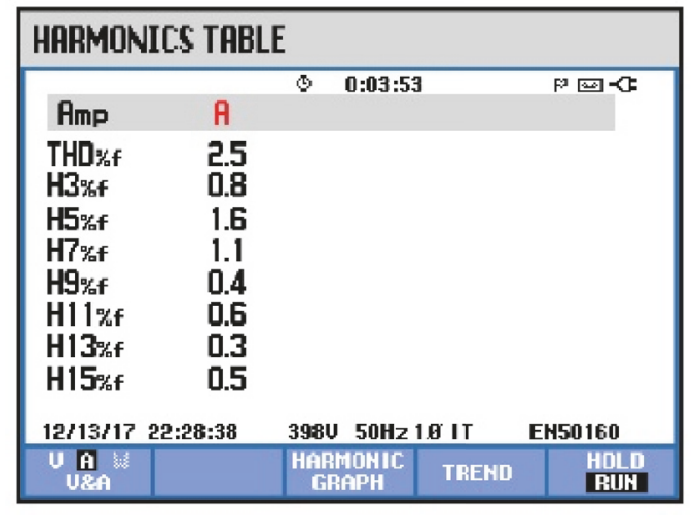

(b) Harmonics table

FIGURE 10: Waveform and harmonics table of current on ac side with feedforward harmonic mitigation strategy. 
mitigation strategy. However, because the theoretical analysis does not consider the effect of PWM dead zone and control delay, it cannot completely eliminate the harmonic current. At the same time, it can be explained that after the 3rd, 5th, and 7th harmonic signal are superimposed in the PWM modulation wave, the other order harmonics currents cannot be suppressed.

\section{Conclusion}

Based on the dynamic phasor method, a harmonic analysis model of SPVSC was established, which takes the controller into consideration. The proposed model is used as a tool to analyze the generation mechanism of harmonic as well as the harmonic interaction between the ac and dc side. The harmonic currents injecting to the grid from SPVSC can be mainly carried out in two ways: external excitation and internal interaction. With the internal interaction between ac and dc side, SPVSC generates series of low-order odd harmonic currents on ac side and series of low-order even harmonic voltages on dc side. With the external excitation, the distorted grid voltages will exacerbate the generation of harmonic currents on ac side. According to the generation mechanism, a feedforward control strategy was put forward to mitigate the harmonic currents from SPVSC which has clear physical meaning, fast calculation speed, and robustness. Meanwhile, it avoids the design of controller parameter and will not affect the stability of the system. Simulation and experimental results are finally presented to verify the proposed harmonic analyzed model and feedforward harmonic mitigation strategy.

\section{Conflicts of Interest}

The authors declare that there are no conflicts of interest regarding the publication of this paper.

\section{References}

[1] Y. Han, X. Fang, P. Yang, C. Wang, L. Xu, and J. M. Guerrero, "Stability analysis of digital controlled single-phase inverter with synchronous reference frame voltage control," IEEE Transactions on Power Electronics, no. 99, 2017.

[2] R. I. Bojoi, L. R. Limongi, D. Roiu, and A. Tenconi, "Enhanced power quality control strategy for single-phase inverters in distributed generation systems," IEEE Transactions on Power Electronics, vol. 26, no. 3, pp. 798-806, 2011.

[3] T. Dragicevic, X. Lu, J. C. Vasquez, and J. M. Guerrero, "DC Microgrids - Part I: A Review of Control Strategies and Stabilization Techniques," IEEE Transactions on Power Electronics, vol. 31, no. 7, pp. 4876-4891, 2016.

[4] E. Romero-Cadaval, B. Francois, M. Malinowski, and Q.-C. Zhong, "Grid-connected photovoltaic plants: An alternative energy source, replacing conventional sources," IEEE Industrial Electronics Magazine, vol. 9, no. 1, pp. 18-32, 2015.

[5] D. Dong, T. Thacker, I. Cvetkovic et al., "Modes of operation and system-level control of single-phase bidirectional PWM converter for microgrid systems," IEEE Transactions on Smart Grid, vol. 3, no. 1, pp. 93-104, 2012.
[6] R.-J. Wai, C.-Y. Lin, Y.-C. Huang, and Y.-R. Chang, "Design of high-Performance stand-alone and grid-connected inverter for distributed generation applications," IEEE Transactions on Industrial Electronics, vol. 60, no. 4, pp. 1542-1555, 2013.

[7] S. B. Kjaer, J. K. Pedersen, and F. Blaabjerg, "A review of singlephase grid-connected inverters for photovoltaic modules," IEEE Transactions on Industry Applications, vol. 41, no. 5, pp. 12921306, 2005.

[8] Q. Zhong, J. Feng, L. Lin, G. Wang, and H. Li, "Graphical presentation of harmonic operating principles in voltage source converter with sparse vector methods," IET Generation, Transmission \& Distribution, vol. 11, no. 4, pp. 1033-1038, 2017.

[9] M.-S. Karbasforooshan, M. Monfared, and M. Dogruel, "Application of the harmonic control arrays technique to single-phase stand-alone inverters," IET Power Electronics, vol. 9, no. 7, pp. 1445-1453, 2016.

[10] Z. Wu, Y. Zou, C. Wang, Y. Zhang, and Z. Zhang, "A performance improvement technique for single-phase PWM rectifier," in Proceedings of the 2009 IEEE 6th International Power Electronics and Motion Control Conference, (IPEMC '09), pp. 1638-1642, China, May 2009.

[11] J.-L. Gao, Y.-J. Zhang, F. Lin, and Q.-L. Zheng, "Research on harmonic current elimination method of single-phase PWM rectifiers," Proceedings of the Chinese Society of Electrical Engineering (CSEE), vol. 30, no. 32, pp. 32-38, 2010.

[12] K. Zhou, Z. Qiu, N. R. Watson, and Y. Liu, "Mechanism and elimination of harmonic current injection from single-phase grid-connected PWM converters," IET Power Electronics, vol. 6, no. 1, pp. 88-95, 2013.

[13] A. Kulkarni and V. John, "Mitigation of lower order harmonics in a grid-connected single-phase PV inverter," IEEE Transactions on Power Electronics, vol. 28, no. 11, pp. 5024-5037, 2013.

[14] R. Teodorescu, F. Blaabjerg, M. Liserre, and P. C. Loh, "Proportional-resonant controllers and filters for gridconnected voltage-source converters," IEE Proceedings Electric Power Applications, vol. 153, no. 5, pp. 750-762, 2006.

[15] M. Castilla, J. Miret, J. Matas, L. G. de Vicuña, and J. M. Guerrero, "Control design guidelines for single-phase gridconnected photovoltaic inverters with damped resonant harmonic compensators," IEEE Transactions on Industrial Electronics, vol. 56, no. 11, pp. 4492-4501, 2009.

[16] P. Mattavelli and F. P. Marafao, "Repetitive-based control for selective harmonic compensation in active power filters," IEEE Transactions on Industrial Electronics, vol. 51, no. 5, pp. 10181024, 2004.

[17] S. Jiang, D. Cao, Y. Li, J. Liu, and F. Z. Peng, "Low-THD, fast-transient, and cost-effective synchronous-frame repetitive controller for three-phase UPS inverters," IEEE Transactions on Power Electronics, vol. 27, no. 6, pp. 2994-3005, 2012.

[18] Y. Yang, K. Zhou, and F. Blaabjerg, "Current harmonics from single-phase grid-connected inverters-examination and suppression," IEEE Journal of Emerging and Selected Topics in Power Electronics, vol. 4, no. 1, pp. 221-233, 2016.

[19] S. R. Sanders, J. M. Noworolski, X. Z. Liu, and G. C. Verghese, "Generalized averaging method for power conversion circuits," IEEE Transactions on Power Electronics, vol. 6, no. 2, pp. 251259, 1991.

[20] N. Kroutikova, C. A. Hernandez-Aramburo, and T. C. Green, "State-space model of grid-connected inverters under current control mode," IET Electric Power Applications, vol. 1, no. 3, pp. 329-338, 2007. 
[21] J. Kwon, X. Wang, F. Blaabjerg, C. L. Bak, V. Sularea, and C. Busca, "Harmonic interaction analysis in a grid-connected converter using harmonic state-space (HSS) modeling," IEEE Transactions on Power Electronics, vol. 32, no. 9, pp. 6823-6835, 2017.

[22] Q. Zhong, L. Lin, G. Wang, Y. Zhang, and Z. Wu, "Harmonic analysis model for voltage source converter under unbalanced conditions," IET Generation, Transmission \& Distribution, vol. 9, no. 1, pp. 12-21, 2015.

[23] J. B. Kwon, X. Wang, F. Blaabjerg, C. L. Bak, A. R. Wood, and N. R. Watson, "Harmonic instability analysis of a singlephase grid-connected converter using a harmonic state-space modeling method," IEEE Transactions on Industry Applications, vol. 52, no. 5, pp. 4188-4200, 2016.

[24] P. Č. Stefanov and A. M. Stanković, "Modeling of UPFC operation under unbalanced conditions with dynamic phasors," IEEE Transactions on Power Systems, vol. 17, no. 2, pp. 395-403, 2002. 


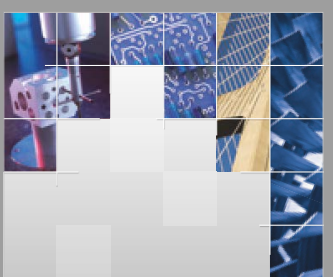

\section{Enfincering}
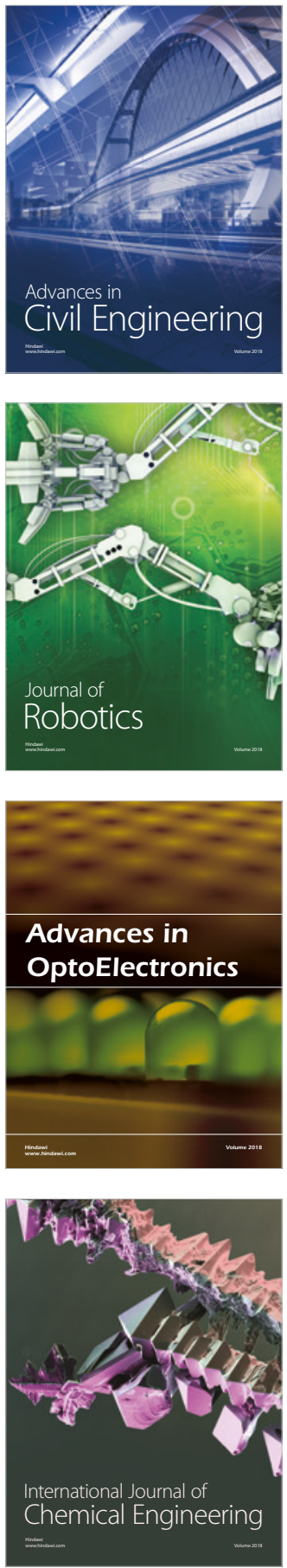

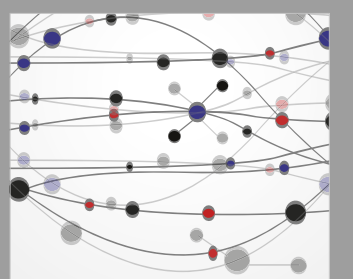

\section{Rotating \\ Machinery}

The Scientific World Journal

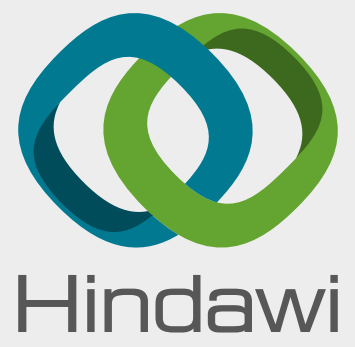

Submit your manuscripts at

www.hindawi.com
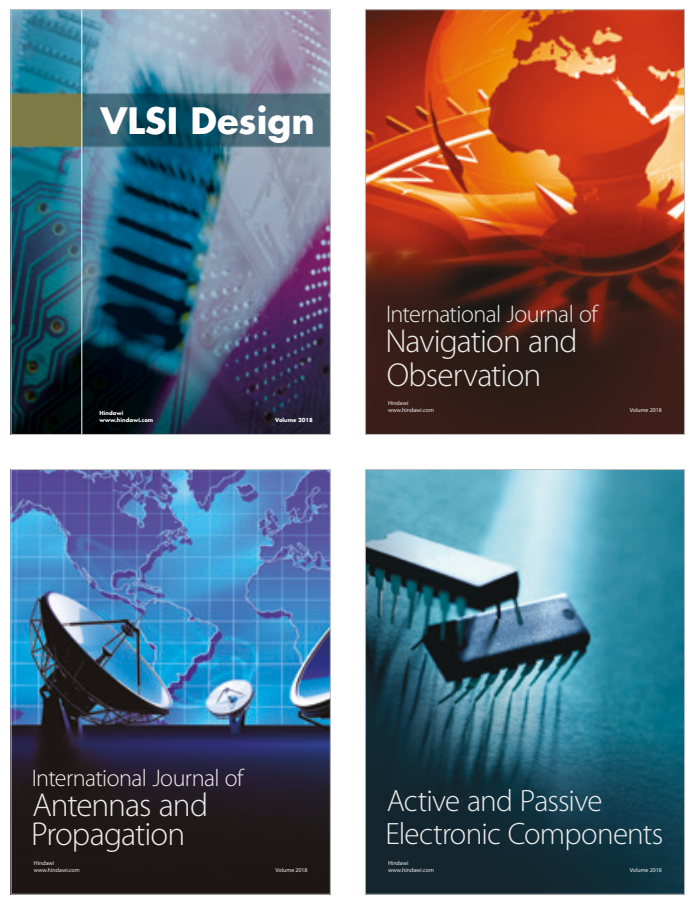
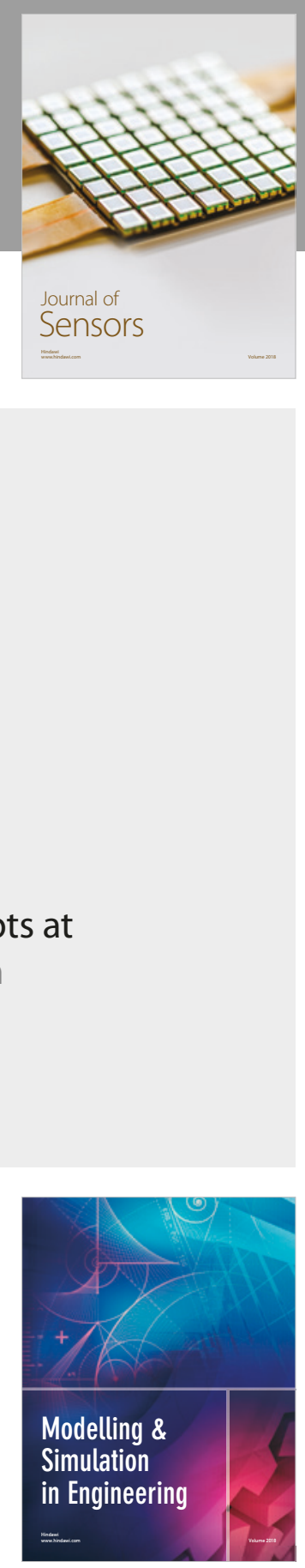

\section{Advances \\ Multimedia}
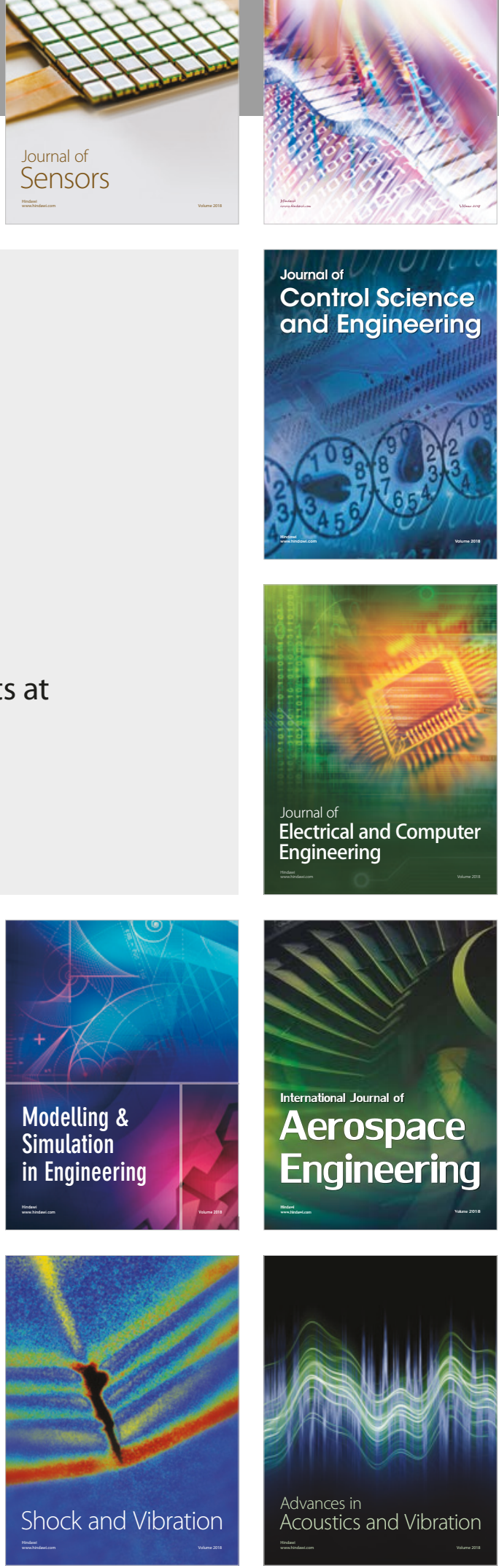